REVISTA DE DERECHO UNED, NÚM. 27, 2021

\title{
EL ANCESTRAL CASTIGO DEL SIGLO XXI
}

\section{THE ANCESTRAL PUNISHMENT OF THE 21ST CENTURY}

\author{
José EMILIo MARquÉs SuÁREZ
}

Doctorando UNED

Investigador en formación en la Escuela Internacional

de Doctorado de la UNED.

Programa de Doctorado: Unión Europea.

Email: emarques4@alumno.uned.es

Sumario: I. Introducción. I.A. Técnicas de Instrumentalización para el encuadre noticioso de la criminalidad. I. A. 1. AGENDA SETTING. I. A. 2. FRAMING. II. La cultura de la cárcel desde tiempos ancestrales. III. La concepción carcelaria desde la antigüedad. IV.La cárcel en la Edad Media. V. De lo Ancestral a lo Moderno. VI. Reformas carcelarias contemporáneas. VII. Nuestra actual penología carcelaria. VIII. Inteligencia Artificial y su beneficiosa introducción en el sistema penitenciario. VIII. A. Algunos datos cuya recogida es imprescindible para la perfilación y pronóstico de las carreras mediante la I.A: VIII. A. 1. Histograma genético. VIII. A. 2. Historial médico. VIII. A. 3. Alteraciones físicas o mentales. VIII. A. 4. Malformaciones congénitas. VIII. A. 5. Violencia familiar. VIII. A. 6. Desarrollo psicomotriz. VIII. A. 7. Hiperactividad. VIII. A. 8. Grupo de pares. IX. La estigmatización de la cárcel. X. Conclusiones.

Resumen: Este trabajo hace un repaso en la evolución de las penas privativas de libertad y muestra su progreso a lo largo del tiempo. Observaremos en él los cambios sociales que pudieron haber influido en la concepción y desarrollo de estas, valorando a su vez si los mismos, de haberse producido, han hecho que la sociedad actual haya desechado la misma como pena prioritaria destinada al 
castigo de las personas tras el quebrantamiento de las normas impuestas por el legislador, dada la aparición de nuevas formas de control social.

Interesa igualmente saber si estas innovaciones en materia de observación y vigilancia, tecnológicas en su mayoría, acompañan el devenir de las condenas o, por el contrario, la sociedad en general y el legislador en particular obvia este tipo de sistemas continuando con medidas de castigo más propias de los ancestrales métodos de control que del actual y moderno siglo XXI.

Es una preocupación, la de la concepción de los cambios sociales en materia de "castigo" que interesa en aras de saber, no sólo en qué paradigma se desenvuelve nuestro sistema penitenciario español actual, sino en qué aspectos ha cambiado la esencia penológica desde el punto de vista social.

Palabras clave: Cárcel. Evolución. Sistema Penitenciario. Medidas de control. Intimidad.

Abstract: This project reviews the evolution of custodial sentences and shows their progress over time. We observe in it the social changes that may have influenced their conception and development, assessing at the same time whether they, having happened, have made current society to have discarded it as a priority penalty for the punishment of people after the violation of the rules imposed by the legislator, due to the emergence of new ways of social control.

It is also interesting to know whether these innovations in the field of observation and surveillance, mostly technological ones, are attached to the fore coming sentences or, on the contrary, society in general and the legislator in particular takes for sure this type of systems, carrying on with punishment measures, more typical of ancestral control methods rather than current and modern 21st century ones.

The conception of social changes dealing with punishment is a relevant concern in order to know, not only what paradigms the Spanish penitentiary system is developing but also what aspects the penal essence has changed from a social point of view.

Keywords: Jail. Evolution. Penitentiary System. Control measures. Privacy.

Recepción original: 24-11-2020

Aceptación original: 14-1-2021 


\section{INTRODUCCIÓN.}

El Tribunal Constitucional Español sentencia que uno de los Derechos Fundamentales más sacrificado durante el encarcelamiento es el derecho a la intimidad. Se pone así de relieve que las consecuencias más dolorosas de la pena privativa de libertad es la perdida de intimidad por parte de los que sufren esa especial sujeción bajo la supervisión de una Institución, sea penitenciaria o policial.

Este mismo Tribunal añade que pueden considerarse ilegítimas aquellas medidas que la reduzcan más allá de lo que la ordenada vida en prisión requiere, constituyendo una clara violación de la intimidad ${ }^{3}$.

En ese contexto quedan necesitadas de autorización muchas actuaciones que normalmente se contemplan como intimas o privadas y que requieren de especial vigilancia, con medias activas o pasivas impuestas para garantizar la seguridad dentro de las cárceles.

El devenir de nuestras leyes y jurisprudencia han llegado a recoger este derecho a la intimidad, también intramuros, como uno de los derechos personales que implica la existencia de un ámbito propio y reservado frente a la acción y conocimiento de los demás, necesario, según las pautas de nuestra cultura, para mantener una calidad mínima de la vida humana ${ }^{4}$.

Esa intimidad se ve en no pocas ocasiones vulnerada cuando una persona adquiere la condición de reo de la justicia y uno de los medios más utilizados para la divulgación de información, la televisión, utiliza programas donde la prisión impuesta a determinados sujetos, unos con renombre social otros por la alarma que han ocasionado sus crímenes, es noticia junto con otros aspectos de la criminología o la penología.

Se instrumentaliza así, el Derecho penal y la Política criminal a través de uno de los "mass media" más poderoso para atender los problemas sociales a la vez que ganan cuotas de audiencia. Esto se lleva a cabo fundamentalmente mediante dos técnicas.

3 S.T.C. 89/1987, F.J. $2^{\circ}$. Y S.TC. 57/1994, F.J. $5^{\circ}$.

4 C.E. Art. 18. Y S.T.C. 231/1998, F.J. $3^{\circ}$.

(C) UNED. Revista de Derecho UNED, núm. 27, 2021 


\section{I.A. Técnicas de Instrumentalización para el encuadre noticioso de la criminalidad.}

\section{I.A.1. AGENDA SETTING.}

Consistente en el fenómeno de tematizar la agenda de noticias, es decir, los medios de comunicación se arrogan la facultad de establecer cuáles temas son relevantes para la sociedad y cuáles no. Decidiendo además que tipo de delincuencia van a situar en el debate público de actualidad, con alcance socio - político.

Se produce de esta manera, una presión e influencia, tanto en los poderes, como puede ser el legislativo, para que actúe de una manera determinada respecto al tema elegido, como ante la opinión pública para que asuma explícitos sistemas de castigo, verbigracia la cárcel, como idóneos e imprescindibles para el control de la delincuencia.

\section{I.A.2. FRAMING.}

Es un encuadre noticioso que va dirigido a lograr en el público una opinión sesgada y rápida de una determinada noticia.

Mediante estas técnicas se consigue que el oyente no se pare a pensar en que consiste el encierro de una persona. Rara vez se maneja el término "cárcel" con el rigor necesario por parte de los medios de comunicación y menos veces aún se opta por explicar a la audiencia de dónde viene el castigo o qué es la prisión. Llegando incluso a manejar los años de condena con la frivolidad de quien no puede imaginar cuáles son los efectos que causa el aislamiento social en un sujeto.

En los últimos años, debido al aumento de la información sobre hechos delictivos y al auge de determinados programas o viceversa, se ha generado en los ciudadanos un aumento del miedo y temor a poder ser víctimas de delitos.

Lo anterior contribuye a instaurar un sentimiento de inseguridad que en muchos casos no se corresponde con un aumento real de la delincuencia.

El marco socio - legislativo anteriormente descrito quebranta el respeto debido a derechos fundamentales, como la intimidad, un de- 
recho inherente a la persona, no afectado por la condena y que la legislación española garantiza explícitamente ${ }^{5}$.

La afectación de la intimidad, aún bajo especial sujeción, forma parte de la esfera personal de los sujetos y sólo será posible su vulneración mediante decisión judicial, disponiendo en todo caso que ello se realice con el respeto y dignidad debida a la persona, no constituyendo nunca trato degradante alguno ${ }^{6}$.

Desde los medios de comunicación se conciencia a la ciudadanía sobre la conveniencia de utilizar la prisión como única respuesta social al delito. No se deja lugar a un planteamiento alternativo de otras formas de control. Los poderes públicos dedican poco esfuerzo a explicar otras alternativas al encarcelamiento, o los efectos que sobre la persona tiene el encierro.

Es cierto que, en la promulgación de las leyes existe una exposición de motivos cuya redacción explica los criterios orientadores que han dado lugar a su redacción y sus objetivos, pero no es menos cierto que esta información queda, en la mayoría de los casos, "reservada" al conocimiento de los profesionales del derecho.

Incluso los fines reeducativos y reinsertadores que nuestra Constitución tan claramente señala, quedan empañados por la idea de que sólo se podrá conseguir tal finalidad a través del encarcelamiento, algo a lo que el propio texto constitucional contribuye señalando que;

"Las penas privativas de libertad y las medidas de seguridad estarán orientadas hacia la reeducación y reinserción social y no podrán consistir en trabajos forzados. El condenado a pena de prisión que estuviere cumpliendo la misma gozará de los derechos fundamentales de este Capítulo, a excepción de los que se vean expresamente limitados por el contenido del fallo condenatorio, el sentido de la pena y la ley penitenciaria. En todo caso, tendrá derecho a un trabajo remunerado y a los beneficios correspondientes de la Seguridad Social, así como al acceso a la cultura y al desarrollo integral de su personalidad"7.

Los legos en derecho, la opinión pública en general, cuando escuchan las locuciones; pena, privación de libertad o medida de seguridad, lo asociarán inmediatamente con calabozo y encarcelamiento de un sujeto, formándose una única idea de castigo serio y seguro, el

5 L.O.G.P. 1/1979, de 26 de septiembre. Art. 3.

C.E. de 1978. Art. 10 y 15.

C.E. de 1978. Art. 25.2. 
de la prisión. Una idea que no parece haber cambiado con el paso de los siglos.

\section{LA CULTURA DE LA CÁRCEL DESDE TIEMPOS ANCESTRALES.}

El encarcelamiento, ha sido desde siempre una de las primeras manifestaciones, que si bien no obedecía a la idea del castigo sí a la del aseguramiento de la persona hasta que esta pasaba a disposición de las autoridades por las que iba a ser juzgada.

Se forma así ese caldo de cultivo, del que aún no nos hemos desprendido y donde se consolida la cenagosa idea de que la cárcel es la única forma de garantizar el sometimiento de las personas a la justicia.

La cultura carcelaria la podemos situar en las ancestrales corrientes de pensamiento llevadas a cabo por filósofos o sociólogos, entre otros, hasta llegar a nuestros días. Todo un recorrido que a través de las diferentes épocas se completa con las actuales legislaciones en materia de derechos humanos o derechos fundamentales como los recogidos hoy en día por las modernas legislaciones.

Las sociedades se fueron desarrollando y evolucionando a medida que lo hizo su pensamiento, porque la historia no puede ser independiente del pensamiento social de cada época.

Por tanto, si analizamos los antecedentes, ideologías y progresos que han venido explicando la evolución de la cárcel, sabremos si socialmente hemos conseguido cambiar el paradigma en que nos hemos venido moviendo durante siglos.

Así nunca tan acertadas fueron las palabras de Bernaldo de Quirós cuando afirmaba que "la historia como la naturaleza no camina a saltos, ya que en sus eras se conservan las improntas de sus predecesores". Es por ello, que los diferentes momentos históricos, han sido y son, causa y efecto de esta evolución.

\section{LA CONCEPCIÓN CARCELARIA DESDE LA ANTIGÜEDAD.}

En la Antigüedad la intimidad como Derecho, ni tan siquiera se barajaba, era esta una idea fuera de aquel contexto social. No sólo eso, era un concepto ignorado por el propio sujeto que nunca había 
gozado de espacios reservados a mayores intimidades que aquellas propias de sus necesidades fisiológicas.

Tampoco podemos hacer referencia a la "dignitas" social o reconocimiento de excelencia personal, ya que todo ello fue evolucionando en función de cada cultura y dentro de ella de sus costumbres, ideologías, creencias o moral.

En términos carcelarios tampoco cabe hablar de lugar digno o íntimo que equivaliese a tales ideas.

Una de las primeras referencias históricas que encontramos sobre la cárcel aparece en los textos sagrados. Narra la reclusión de personas y referencia las indignas condiciones de hacinamiento a las que estaban sometidas. Deja rastro del carácter custodio que se adoptaba a través del encarcelamiento. Es el Génesis primer libro del Pentateuco que forman los cinco libros sagrados de la Ley o Tanaj, en su versículo 41.14., donde se habla de la disposición de José ante el Faraón y las indignas condiciones en las que se encontraba, harapiento y desatendido.

Muchas otras referencias dejan constancia del uso al que iban destinados los ancestrales lugares de presidio, aunque bien es cierto que son difíciles de rastrear todos ellos por la utilización diversa de su terminología, pues se habla de reclusorios, campos, mazmorras, calabozos y otros.

En Atenas se descubrieron durante la realización de unas excavaciones en el Ágora o Centro de la Actividad Sociopolítica donde se impartía justicia en la época de PLATÓN (427 - 347 a. C.), evidencias de que allí existió una cárcel cuyo destino era la permanencia del reo en ella hasta la celebración del juicio. Y en su caso hasta la ejecución de la condena, que solía derivar en pena capital.

Así, el caso de SOCRATES según relatos del propio PLATÓN ${ }^{8}$.

No existe certeza sobre el empleo de la prisión como castigo por aquel entonces. Ni condenas de prisión a cadena perpetua en aquella época. Muchos autores coinciden en negarlo, aunque en Roma sí admiten que llegaron a utilizar los lugares de encarcelamiento para recluir al deudor hasta que el acreedor quedase satisfecho de la cantidad adeudada.

Otros encuentran evidencias del encarcelamiento como castigo e incluso mantienen que la pena de muerte podía conmutarse por la

8 PLATÓN. Diálogos. Tomo III. Gredos, Madrid. 1997. Pág. 24 - 29.

(C) UNED. Revista de Derecho UNED, núm. 27, 2021 
cadena perpetua en función del carácter de "ciudadano" que ostentase la persona ajusticiada ${ }^{9}$.

La concepción de la cárcel como lugar de encierro fue motivo de preocupación por parte de pensadores y filósofos. HERÁCLITO, PITÁGORAS, SÓCRATES O PLATÓN, entre otros, intentaron con el encarcelamiento dar solución a los crímenes y luchar contra los delincuentes.

PLATÓN en el libro noveno de "Las Leyes", alude a la cárcel, al castigo, al látigo y a la muerte, pero también a la pena de encarcelamiento para los criminales.

Un ancestral mundo carcelario lleno de miseria, desigualdades y despotismo del que en algunas ocasiones sólo se libraba quien ostentaba cierta condición social o influencia política.

El propio SÉNECA hacía distinciones en su obra "De la Cólera" argumentando que el castigo, por dañoso, no cabe su aplicación al hombre bondadoso y sí al que mantiene una conducta perniciosa que solía coincidir con el ser marginal.

Justificaba así el castigo como medida retributiva. Compara al gobernante con el médico y señala el recurso de los castigos extremos para quienes no responden a otro tratamiento. Argumentos filosóficos que no estaban dirigidos a recuperar al delincuente, sino a eliminarlo de la sociedad si no respondía a un reajuste moral.

En los siglos II y III, época en que ULPIANO desarrolla su actividad como jurista, este define la justicia como la continua y perpetua voluntad de dar a cada quien lo que le corresponde.

Hasta el siglo V d. C. se mantuvo una relación con la justicia muy basada en un desarrollo social de economía primitiva y culto a los dioses, donde el sometimiento del hombre se llevaba a cabo a través de la esclavitud o el escarmiento para la reparación del mal. Remedio infalible para la purga del infractor en un espacio carcelario misero y lúgubre.

Un método, el del castigo que purificaba el alma del reo a través del correctivo, amén de dar ejemplo a otros posibles infractores.

Si bien es cierto que, en todos los textos antiguos, se argumenta y suscribe que la cárcel surgió para dar custodia a las personas que iban a ser puestas a disposición de la justicia y no para el castigarlas.

9 MOMMSEN, Théodore. Derecho Penal Romano. Anacleta, Pamplona. 1999. Pág. 402. 
El mismo ULPIANO lo señalaba así en su compilación del Digesto de Justiniano.

\section{LA CÁRCEL EN LA EDAD MEDIA.}

Esta época fue una continuidad de barbarie y calamidad social, de brutalidad y crueldad, donde la justicia asumía el escarmiento como un método, casi único, para doblegar al pueblo. En toda la Edad Media, que fechamos desde el siglo IV al siglo XV d.C. no faltan referencias que nos señalan la cárcel como lugar preferente de castigo.

Es cierto que el encierro continuaba perfilándose como lugar de custodia, pero se iba más allá transgrediendo la ética de los custodios, ya que, dentro de aquellos lugares de reclusión, donde imperaba el hacinamiento y la falta de higiene, sometían al reo a terribles castigos o le daban muerte en lugares públicos, justificando tales prácticas en la lucha contra la delincuencia y en evitar así la reincidencia.

Conforme la teoría de "el fin de la pena" se trataba de esta forma la prevención especial dirigida al delincuente encarcelado y la prevención general dirigida a la sociedad.

El objetivo final era generar miedo, mediante el trato degradante y cruel de aquel que se atrevía a transgredir las normas sociales. Una época que destacó por el suplicio, el tormento y las grandes angustias de los encarcelados a manos del libre albedrío de quienes se encargaban de su custodia.

El cautiverio punitivo y el abandono progresivo de la idea que se tenía de la cárcel, destinada sólo para lugar de custodia, apareció coincidiendo con la llegada a España del Derecho Romano, otorgándole mayor ámbito a la prisión. Ya no solamente se entendería como una Institución preventiva, sino como un lugar de cumplimiento de penas efectivas.

Aunque ciertamente era un concepto de condena alejado del sentido moderno que hoy se tiene de la pena privativa de libertad.

La cárcel continuó diversificando su hegemonía a lo largo de los siglos, dando lugar a la aparición de lugares de encarcelamiento muy diversos, unos a manos de Señores feudales que poseían sus propias Casas de Justicia, otros como Prisiones Reales, Eclesiásticas e incluso Municipales entre una amplia variedad. Y todas ellas con un elemento común que nunca desapareció, el ultraje de la per- 
sona. Unas veces fundido entre castigo y pecado, términos que continuaban fundiéndose con igual prodigalidad a la hora de sentenciar, otras por los excesos que intramuros se llevaban a cabo en materia de malos tratos, vejaciones, humillaciones o torturas.

Se perpetuaba igualmente el hacinamiento de reos, especialmente en las cárceles laicas, prisiones del Estado donde iban destinados los enemigos del sistema o enemigos de la monarquía.

Una mezcolanza sometida al arbitrio de los gobernantes. Cárceles que no garantizaban igualdades para los que allí iban derivados.

Una época en la que la distinción de clases y trato iba en función, una vez más, de la relevancia o condición social ostentada.

\section{DE LO ANCESTRAL A LO MODERNO.}

Las cárceles de la época Moderna no experimentaron grandes o vertiginosos cambios, ni en sus estructuras ni en sus sistemas de ejecución, el transcurso de estos fue lento.

En el siglo XVI se dan las primeras preocupaciones y movimientos sociales por dispensar mejor trato a los encarcelados, modificando paulatinamente las estructuras de la Edad Media al crearse un nuevo concepto de sociedad que trataría mejor a sus conciudadanos, especialmente a las clases más desfavorecidas que constituían el mayor número de población reclusa.

Pero lo moderno no fue siempre sinónimo de mejora para los reclusos, ya que en esta época se diseñaron también muchos de los instrumentos de tortura y ejecución, que se vendían como métodos más humanos y efectivos para dar muerte al condenado. Fue el caso, por poner un solo ejemplo de la guillotina. Una herramienta ideada por un médico francés cuyos tintes humanitarios fueron del agrado del Monarca Luis XVI que la calificó de artilugio rápido, seguro, eficiente y limpio para dar muerte al sentenciado. Nada le hacía pensar que él mismo iba a ser guillotinado.

Es verdaderamente una historia de dolor y llanto en la que las ejecuciones publicas cobraban verdadero interés social e incluso se observaban por el pueblo como una auténtica fiesta de distracción a la que acudían personas de todas las edades.

No solo se desarrollaron en este periodo nuevos útiles de ejecución, sino nuevas formas de castigo carcelario. 
Se comienza a utilizar por entonces la pena de galeras para las mujeres. Es quizá el primer referente de cárcel para mujeres. No eran destinadas a remar en los barcos como se hacía con los hombres para que trabajasen moviendo los navíos del comercio marítimo o de vigilancia, sino que aparecen las Casas Galera donde se desarrollaban labores de costura y tareas del hogar bajo la supervisión de religiosas que no dudaban en emplear duros castigos para gobernarlas con firmeza.

Las galeras tanto de hombres como de mujeres llegado el siglo XVII comenzaron a desaparecer, en el caso de unos por los avances en la navegación marítima, en el de las otras porque con la aparición de nuevas normativas judiciales y penitenciarias se equiparaban $\mathrm{u}$ homologaban las condenas y los castigos de ambos.

Se emprende entonces una nueva pretensión, reformar a la persona y no sólo castigarla. No como cabría pensar, a través de métodos didácticos, sino nuevamente con el miedo y la intimidación.

La tortura ya no tiene la finalidad de tormento, pero el castigo corporal se continúa utilizando mediante la fórmula de los trabajos forzados, observando estos como un instrumento reformador del individuo. De esta forma los condenados constituían mano de obra barata y generaban un beneficio para el Estado.

En el siglo XVIII de nuevo regresó la idea de reformar a la persona delincuente. Un gran número de juristas españoles se mostraron interesados por adoptar nuevos sistemas penitenciarios que pudiesen recuperar socialmente al condenado sin que el único método fuese el trabajo corporal, así que con la llegada de Carlos III al reino de España se trató de compaginar el absolutismo con las ideas ilustradas que venían de Europa.

Eran cambios de orientación humanista que influirían en la adopción de políticas criminales para luchar contra la delincuencia, muy acentuada en la época con la aparición del bandolerismo. Una sociedad en la que miseria y dolor continuaban siendo factores dominantes del entorno cotidiano.

Las reformas legislativas que se venían anunciando en España tendrían su referente en figuras europeas influyentes, como Beccaria, Bentham o Howard que conocedores de las cárceles tras visitar muchas de ellas, ofrecían una idea clara de hacia donde tenían que dirigirse los avances humanitarios tan esperados y de los que se hicieron eco en nuestro país figuras como Manuel de Lardizabal, 
quien afirmaba que nuestra legislación penitenciaria de entonces más que reformarse debía hacerse enteramente de nuevo.

\section{REFORMAS CARCELARIAS CONTEMPORÁNEAS.}

Las legislaciones penitenciarias contemporáneas vienen abrigadas bajo el manto de aquellas ideas de Beccaria que abogaban por la moderación de las penas y la dignificación del encarcelado que sufría hambre y suciedad.

Cesare Beccaria fue un adelantado a su tiempo que posteriormente obtendría el apoyo de numerosos juristas de la Época Moderna que reconocerían su trabajo.

Hizo claras alusiones sobre el abuso de la cárcel por parte de los jueces y sobre los efectos que la restricción del derecho a la libertad podía tener en la persona. Incluso se atrevió a señalar otros aspectos personales afectados por el encarcelamiento, como la intimidad o la credibilidad del sujeto.

Aspectos de total actualidad, no solo por la repercusión directa en derechos como la presunción de inocencia sino por la asimilación a la existente "pena de banquillo"10.

Llegado el siglo XIX nacen las ideas de un nuevo espíritu dirigido a modificar los sistemas penitenciarios y aparecen como precursores sistemas importados, como el Sistema Filadelfico o Pensilvánico y Auburn en los que se basaría el sistema progresivo que se forjaría en Europa a mitad del mismo siglo.

Para los mencionados Sistemas progresivos, cuya idea había sido igualmente traída de otros continentes como América y Europa, todo beneficio penitenciario giraba en función del comportamiento de la persona encarcelada. Se descargaba toda responsabilidad en el reo.

Un referente en este tipo de legislación penitenciaria fue el Sistema Montesinos español, que abogaba por la extinción de los castigos corporales y ofrecía la posibilidad al reo de corregirse, premiando la buena conducta y su trabajo, dispensando un trato afable a este y motivándole con comunicaciones familiares.

10 Donde el acusado o Investigado (antes imputado) de un delito, al acudir a un juicio permanece sentado en un banquillo donde escucha todas las pruebas y testimonios que existen contra él. Dando sentido a esta expresión. 
Según Montesinos, la cárcel no estaba para castigar al recluido sino para enmendarle, porque el oficio de la justicia no era vengar sino corregir.

Hay que decir que, pese a todos los esfuerzos e iniciativas, el siglo XIX finalizó con unos sistemas penitenciarios de gran expectativa, pero con una realidad penitenciaria verdaderamente lamentable.

En él destacó Concepción Arenal como visitadora de cárceles, luchadora en favor de los oprimidos, de los pobres, de los desgraciados, y concretamente de los derechos de los presos.

El siglo XX comenzaría nuevamente con la idea de reformar aquellos sistemas sustentados en el castigo, que apartaban al delincuente de la sociedad y mantenían el carácter retributivo de la pena.

Una nueva penología que se desarrollaría en el seno de la llamada Ciencia Penitenciaria y que se ocuparía del delincuente para ofrecerle unas condiciones sociales con finalidad reintegradora. Reformas que no sólo anuncian variaciones legislativas, sino que se iniciarían con modificaciones arquitectónicas como la inauguración de la cárcel Modelo de Barcelona en 1904.

La arquitectura penitenciaria de la Modelo de Barcelona tuvo un gran seguimiento y fueron construidas posteriormente otras de las mismas características en todo el país. Ejemplo de ello fueron Oviedo, Coruña, Lérida o Carabanchel en Madrid, manteniéndose este tipo de estructura hasta la llegada de los Centros Tipo en el último tercio del siglo XX.

Pero pese a todo este esfuerzo el trato indigno y vejatorio que continuaban teniendo los reclusos venía siendo, sino el mismo, de similar semblante, pues en España los cambios prometidos, ecos de las ideas ilustradas que venían de Europa sufrieron un paréntesis con la llegada de la dictadura, no observándose grandes modificaciones legislativas en favor de los derechos del reo hasta la promulgación de la Constitución Española en 1978 y la Ley Penitenciaria de 1979 a la que acompañaría el primer Reglamento de Prisiones de la democracia publicado en 1981.

Las reformas penitenciarias, no fueron una preferencia en ninguna época. Se han promulgado Reglamentos, se han cambiado y modificado Instrucciones de trabajo, pero ha sido tan escaso el interés político - social que no ha habido ninguna propuesta de reforma hacia otro sistema que no sea la reclusión. 
Tal es así que la propia iconografía que hoy exhiben los funcionarios de prisiones data de la época de la dictadura, modificada bajo el mandato de Francisco Franco que quiso dar autoridad y reconocimiento a un Cuerpo que había surgido de las milicias, otorgándoles un emblema que llevase consigo una corona símbolo del poder vinculado al cristianismo de los Reyes Católicos, una palma de laurel cuyo significado advertía del triunfo temporal de la vida sobre la muerte, un perenne laurel atribuido a la persona que vence y permanece, una espada asociada a la justicia, y una rueda dentada que hace alusión al trabajo que "dignifica al hombre y reduce su pena" una frase emblemática utilizada por el imperio alemán en sus campos de trabajo.

\section{NUESTRA ACTUAL PENOLOGÍA CARCELARIA.}

Hemos llegado al sistema actual de penas, abordando un somero repaso de los ancestrales sistemas de encarcelamiento. Y tras un amplio recorrido de siglos seguimos manteniendo la figura de la "jaula" como exhibición de la musculatura del Estado, que parece advertir al ciudadano de la facilidad con que puede ser encerrado, limitando sus derechos más allá del que propiamente afecta a la libertad de movimiento.

Si lo anterior realmente es así, y la prisión parece ser la única forma en que el Estado se hace respetar, habría que preguntarse cuánto hemos avanzado culturalmente desde los primeros tiempos que venimos rememorando si en pleno siglo XXI estamos aún en la fase de expiación de la pena a través del encierro.

Parece que los vientos de la penología de este siglo no soplan aun favorablemente, pese a los avances culturales, científicos y tecnológicos.

En el siglo XVI Cerdán de Tallada afirmaba que la materia de la cárcel no estaba bien recogida ni allegada a lugar cierto. Cinco siglos más tarde podemos afirmar lo mismo, aunque no podemos justificarlo de igual manera.

Hoy estamos provistos de medios que pueden sustituir la cárcel por unas medidas de control que no son el confinamiento del sujeto en una celda.

Sabemos, como sabía Beccaria que existe una gran repercusión del encarcelamiento en la persona; estigmas, patologías que inciden en el comportamiento delictivo o enfermedades sobrevenidas causa de la involución del sujeto o inadaptación al régimen penitenciario. 
Existen distintos programas de tratamiento que hasta la fecha se manejan para abordar situaciones como las anteriormente descritas y que en muchas ocasiones podrían tener mejor desarrollo fuera de los muros de una prisión.

\section{INTELIGENCIA ARTIFICIAL Y SU BENEFICIOSA INTRODUCCIÓN EN EL SISTEMA PENITENCIARIO.}

Novedosos estudios abordan una nueva época en la que ha hecho aparición, junto con los medios telemáticos, la Inteligencia Artificial. Un método, el de la I.A. que más temprano que tarde será de aplicación, no sólo para el cálculo de las penas, sino lo más importante, para dar forma a un nuevo sistema penitenciario que tenga en cuenta los factores etiopatogénicos de la conducta del sujeto y aquellos otros de interés criminológico.

La Inteligencia Artificial dará cuenta de muchos aspectos personales y sociales del delincuente.

La mayoría de los delincuentes que mantienen una conducta violenta han de ser perfilados para poder desarrollar un programa individualizado de forma multiaxial. El sistema de grados penitenciarios ha quedado obsoleto, no sólo no se ajusta a las necesidades actuales del siglo XXI, sino que está basado en parámetros propios de otra época.

El estigma, el rechazo por parte del interno o la apertura a una clasificación basada en grados mixtos dan fe de ello.

De igual manera podremos utilizar la Inteligencia Artificial para la obtención de beneficios en el sistema penitenciario. Un sistema que, parafraseando a Manuel de Lardizabal "más que reformarse debería cambiarse enteramente" 11 .

La criminología como ciencia bebe de numerosas fuentes, como son, el derecho, la psicología o la sociología, entre otras, a las que actualmente se une la de los algoritmos utilizados por la I.A.

No hay nada de misterioso en ella, el único peligro existente es el respeto de los Derechos Humanos y la correcta utilización de sus aportaciones.

11 LARDIZABAL y URIBE de, Manuel (1782). Discurso sobre las penas contraído a las leyes criminales de España para facilitar su reforma. $2^{\mathrm{a}} \mathrm{Ed}$. Imprenta de Repullés. Madrid. 1828.Pág.7. 
Aportaciones para ${ }^{12}$ :

— "Los condenados. Que por su bajo porcentaje de peligrosidad sean merecedores de reducción de la condena o que por el cambio en sus circunstancias sociales se pueda valorar de forma objetiva la suspensión de la condena y su puesta en libertad.

— Los investigados. Que no sean merecedores de la prisión provisional o su valoración haga posible la aplicación de otros métodos, al no ser de aplicación el artículo 503 de la Ley de Enjuiciamiento Criminal donde se regulan los requisitos que concurren para su aplicación.

- La sociedad. Existiría una valoración minuciosa de la peligrosidad del individuo, reforzándose el Estado de Derecho con la puesta en libertad de aquel que puede ser reinsertado y la permanencia en prisión de aquel que no puede ser liberado.

Los beneficios que obtendríamos con la utilización de la I.A. en materia penitenciaria serían sobre todo de amplitud de datos, ayudando al desarrollo de estrategias que tratarían el comportamiento delictivo desde su génesis.

Hoy muchos delincuentes que ingresan en prisión lo hacen con trastornos mentales, que, si bien no han tenido consideración durante el procedimiento penal de eximentes completas, lo tuvieron como eximentes incompletas o atenuantes, pero no evitaron que estas personas terminasen ingresando de igual forma en la cárcel.

En otros casos, las psicopatologías son sobrevenidas, es decir, durante el encarcelamiento el interno se convierte en paciente psiquiátrico, teniendo que tratar su patología dentro del Centro penitenciario donde se encuentra.

La peligrosidad del individuo o la conveniencia de aplicarle una u otra condena, serían dos de las utilidades penitenciarias en las que la Inteligencia Artificial podría estar indicada.

Actualmente este tipo de tecnología se utiliza para desarrollar mapas criminales, estudios sociológicos que recaban datos y circunstancias del delincuente para determinar en qué lugar hay mayor incidencia delictiva.

12 IBAÑEZ LÓPEZ - POZAS, Fernando L. Ponencia: Aplicaciones de la Inteligencia Artificial en el derecho comparado y su posible trasposición al derecho español. Congreso de I.A. y Derechos Humanos. UNED, Madrid. 2019. 
De la misma manera se podrían recabar datos para la adecuación de un programa individualizado de tratamiento penitenciario que se desarrollaría intra o extramuros, en función de esa peligrosidad del penado. Pero también han de ser sociales, sanitarios, familiares y académicos además de judiciales o policiales.

\section{A. Algunos datos cuya recogida es imprescindible para la perfilación y pronóstico de las carreras mediante la I.A:}

\section{VIII.A.1. El Histograma Genético.}

Existen muchas causas para el comportamiento de la conducta humana en toda su diversidad, y lo mismo se aplica a la conducta criminal. La nueva tecnología investigativa abre un espectro de posibilidades de índole biológico, orgánico, congénito o hereditario.

Es imperativo que se actualicen estos descubrimientos e hipótesis por cuanto es necesario reconocer las condiciones fisiológicas, neurológicas, cromosómicas y anatómicas como factores concurrentes de la conducta humana y específicamente en el campo de la conducta violenta que deriva en delito.

Hoy en día existen gran cantidad de estudios que explican la criminalidad desde la perspectiva biológica. No es una moda o patrón, las nuevas investigaciones barajan variables que incluyen enorme variedad de factores físicos como los niveles alterados de serotonina, alteraciones en el lóbulo frontal, ADD Desorden del Déficit de Atención, niveles altos de testosterona combinados con niveles bajos de serotonina, niveles bajos de colesterol y otros.

\section{VIII.A.2. Historial médico.}

La genética es una rama de las ciencias biológicas cuyo objeto es el estudio de patrones de herencia. Características que se trasmiten de padres a hijos. Los genes se forman de segmentos de ADN. La herencia biológica es transmitida de una generación a la siguiente.

También son significativos los hábitos relacionados con determinados consumos para futuros comportamientos. El Síndrome Fetal Alcohólico es causa de anormalidades neurológicas. 
VIII.A.3. Alteraciones físicas o mentales.

Estas pudieran derivarse incluso de un parto prematuro y podrían ser predictoras de futuros comportamientos anómalos en personas nacidas bajo estas circunstancias.

VIII.A.4. Malformaciones congénitas.

Personas que pudieran sufrir algún tipo de retraso mental y no fuesen capaces por sí solas de desarrollarse socialmente en un entorno inadecuado mostrando un potencial de riesgo delictivo.

VIII.A.5. Violencia familiar o escolar.

Toda violencia repercute profundamente en las personas, en su autoestima y frustración como factores concurrentes del futuro comportamiento delictivo.

VIII.A.6. Desarrollo psicomotriz.

Ya que determinados estudios demuestran que la coordinación motriz está claramente relacionada con el rendimiento académico.

De la misma forma que las teorías criminológicas mantenidas por autores como Lombroso y Goring afirmaban que la conducta criminal se debía básicamente a déficits cognitivos, y aunque estas teorías se han ido descartando, existe un número particularmente grande de personas que han cometido delitos en el rango de (80 - 90 puntos de C.I.), que se corresponde con la inteligencia límite.

VIII.A.7. Hiperactividad.

La hiperactividad es algo más que un trastorno simple, negativo y defectuoso. Las personas con TDAH tienen un potencial latente del que nadie habla (como la creatividad, el ingenio, la sensibilidad, entre otros). Pero ser hiperactivo es positivo si tenemos la habilidad de comprender y anticiparnos a tratar el trastorno desde una perspectiva educativa preventiva de determinadas conductas antisociales. Ya que también se puede ser impulsivo y provocar serios conflictos 
no sólo durante la vida académica sino en el mismo clima de convivencia social.

VIII.A.8. Grupo de pares.

La influencia de los amigos, de iguales, en el comportamiento delictivo es importante. Los jóvenes que delinquen tienden a unirse, incluso comenten delitos porque están en grupos. Las bandas son un fenómeno juvenil. Los jóvenes delincuentes tienen amigos delincuentes, se asocian con sus iguales.

Existen como podemos ver muchos factores que podrían correlacionar con la conducta desviada, señalamos solo algunos a modo de ejemplo.

El diseño de programas específicos podría suponer una respuesta positiva a cada caso, de manera que se individualizasen los tratamientos penitenciarios en función de las carencias, patologías, o necesidades del sujeto.

La individualización científica de nuestro actual sistema penitenciario se basa en conceptos anticuados, como las tablas de evaluación de riesgo que se utilizan actualmente y que están diseñadas bajo parámetros propios de otros siglos.

Por ello la inclusión de bases de datos gestionadas a través de la I.A. es una necesidad. Datos supervisados por la ciencia criminológica. Porque rememorando nuevamente a Platón; "la toma de decisiones es imperfecta si solo se basa en datos. Ha de permanecer el conocimiento".

Los beneficios y ventajas de la ciencia no deben ser solo válidos, sino que han de ser responsables y buenos para la sociedad o contexto de aplicación.

La I.A. puede ayudar a valorar con mucha más precisión y de manera más actualizada aquellos factores de riesgo que pueden determinar el ingreso o no de una persona en la cárcel. Y en su caso el diseño de programas de tratamiento adecuados para su posterior desarrollo intra o extramuros.

Es frecuente que se presenten cuadros en la persona indicativos de trastornos de la personalidad, trastornos emocionales, dependencia a las drogas, al alcohol, comportamientos que han interferido e interfieren en la vida personal, familiar y social del sujeto. 
Todos estos antecedentes, que han llevado al sujeto a una vida marginal, delictiva o violenta, condicionan conductas agresivas y de riesgo.

La amplitud de los mismos y limitación de los medios penitenciarios utilizados actualmente invalida la elaboración de un nuevo sistema.

Un gran porcentaje de personas que ingresan en un Centro Penitenciario presentan rasgos conductuales que indican la presencia de algún trastorno mental, como demencia, ansiedad, depresión o determinadas filias que los han llevado ante la justicia para posteriormente cumplir condena.

Nos hemos de plantear si con los medios tecnológicos que actualmente podríamos manejar dando el paso de incluir la I.A. en el diseño de un nuevo sistema penitenciario, lo primero ha de ser el ingreso carcelario del infractor o por el contrario la ejecución de un programa adecuado a sus patologías, filias y antecedentes.

\section{LA ESTIGMATIZACIÓN DE LA CÁRCEL.}

De poco serviría realizar un plan individualizado de ejecución penitenciaria, si estigmatizamos previamente a la persona antes de declararle tan siquiera culpable.

Para la consecución del objetivo de reinserción social, si es que creemos en ella, hemos de abordar seriamente un pacto con los medios de comunicación para el iniciado siglo XXI, con arreglo a las nuevas formas de entender la intimidad personal de los encarcelados, sean estos detenidos, presos preventivos o penados.

$\mathrm{Y}$ a este respecto las palabras de Victoria Kent "O creemos que nuestra función sirve para modificar al delincuente o no lo creemos. En el caso de no tener esta fe, todas las mazmorras y el repertorio entero de castigos será poco".

Por tanto, en el siglo XXI, siglo de las comunicaciones tecnológicas, hay que tomar la decisión de implantar leyes que finalicen con la estigmatización del delincuente, algo que imposibilita el cumplimiento del mandato constitucional de reeducación y reinserción.

No podemos continuar con la práctica de exhibir al reo como se venía haciendo en las ancestrales ejecuciones públicas, porque entonces nos será imposible terminar con la prisión como pena estrella de nuestro ordenamiento jurídico. 


\section{CONCLUSIONES.}

Los métodos de control social ante el delito en lo que al encarcelamiento se refiere han variado poco desde los ancestrales pensamientos carcelarios hasta el actual siglo XXI en que la pena estrella continúa siendo el encierro de la persona.

Nuestro estudio no arroja grandes cambios en este sentido ya que no parece que el progreso de los diferentes sistemas penitenciarios haya experimentado otras alternativas y desechado esta.

Tampoco los valores fundamentales de dignidad o derecho a la intimidad de la persona parecen prevalecer en una sociedad que consume espectáculos públicos en los medios de comunicación. Se sigue teatralizando al delincuente como se hacía en la Edad Antigua, antes en las plazas, hoy en las redes sociales.

Ello dificulta en gran medida, como venimos señalando, el mandato constitucional de reeducación y reinserción debido a la estigmatización social que se hace del reo e influye en el tratamiento individualizado empeorando el pronóstico final. Igualmente vulnera derechos como la presunción de inocencia o el derecho a la tutela judicial efectiva.

El pensamiento social está altamente influido por los poderes públicos y los medios de comunicación. Se continúa enviando al ciudadano el mensaje de que el encierro es la mejor forma de hacer justicia. Los cambios sociales no han provocado que la prisión tenga una aplicación de ultima ratio.

Nos ocupábamos en este trabajo de los tipos de penas que fueron apareciendo a lo largo de los siglos, y manteníamos que las Casas Galera para mujeres estaban destinadas al duro trabajo de estas.

También que conformaban uno de los primeros antecedentes como lugar de custodia solo para mujeres. Y una de las primeras manifestaciones de la prisión como castigo, que ya no iría destinada exclusivamente a la custodia hasta la disposición judicial.

Las mujeres en la España de la época y en toda Europa, eran en su mayoría castigadas a duras labores en régimen de recogimiento. Labores del hogar.

Pues bien, aún se mantiene en nuestro actual Reglamento Penitenciario, un vestigio de aquella época, que las labores domésticas sólo son consideradas para mujeres, de ello da fe el artículo 82 del R. $\mathrm{P}^{13}$.

13 R. P. 190/1996, de 9 de febrero. Art. 82.2. 
Pese a tener todos los medios a nuestro alcance y los profesionales que pueden desarrollar y diseñar nuevos sistemas penitenciarios basados en teorías y pensamientos criminológicos, estos se están obviando deliberadamente debido a la aplicación de políticas erróneas influenciadas por otras fuentes que no se basan en datos científicos que sí ofrece la criminología. Son los medios de comunicación, las ideas políticas, los movimientos de víctimas, los grupos de presión.

La política criminal continúa sin tener la objetividad necesaria que le otorga la ciencia criminológica, ya que está dirigida a intereses político - sociales y no penitenciarios.

La aparición de la prisión permanente revisable es un paso atrás, nos regresa al siglo XIX, época en la que con la aparición e implantación de los sistemas progresivos se derivaba toda responsabilidad de reinserción en el reo.

Se mantiene en el siglo XXI un anticuado modelo de gestión penitenciaria en detrimento del mandato constitucional de reeducación y reinserción pese a la aparición de nuevas tecnologías, sin dedicar suficientes recursos a la investigación y desarrollo de un nuevo sistema penitenciario multiaxial que recoja aspectos psicopatológicos, sanitarios, sociales, familiares y educativos entre otros.

Es evidente que, la creencia de que la "jaula", como ya habíamos señalado, constituye el único medio de exhibición muscular que el Estado tiene para ganarse la respetabilidad y mantener el orden, no se ajusta a la época actual.

Durante la pandemia del COVID 19, Instituciones Penitenciarias envió a sus casas a más de cinco mil trescientos reclusos a los que aplicó medios telemáticos. Hemos tenido que pasar por una pandemia para cerciorarnos de que el sistema penitenciario que estamos empleando no es ni infalible ni adecuado y que existen otras vías de ejecución.

Es necesaria la potenciación en el uso de esos medios electrónicos y telemáticos, así como la inclusión de la I.A. en el desarrollo de una nueva legislación penitenciaria más acorde a la sociedad actual. No ha de existir opacidad respecto a los datos utilizados, ni miedos infundados en su recogida, se han de respetar las normas relativas a la protección de datos y garantizar la fiabilidad del sistema.

El miedo a la cárcel como lugar de suplicio y tormento, de grandes angustias sociales, fue propio de la edad media, como hemos señalado a lo largo de este trabajo, aspectos contrapuestos a la reedu- 
cación y reinserción. Y si bien es cierto que hace menos de un siglo hemos abandonado aquellos ancestrales métodos para dar muerte al reo, ideados desde el siglo XVI, la esencia del ultraje se eterniza en nuestras cárceles.

El problema penitenciario, siempre de actualidad debe preocuparnos a todos, ya que todos, aún los más honrados, estamos expuestos, por un error judicial o por otras causas, a sufrir los horrores de nuestras prisiones. Así lo manifestaba en 1911 Francisco Cabrerizo.

El progreso y devenir de las condenas no han resuelto las cuestiones de intimidad a las que aludíamos al principio de nuestro estudio y que se tornan importantes cuando observamos el problema penitenciario desde el plano de los derechos fundamentales. El Tribunal Constitucional ha tenido numerosos pronunciamientos al respecto señalando la existencia de un ámbito propio y reservado frente a la acción y conocimiento de los demás. Y, asimismo señala el Constitucional; que el derecho a la intimidad atribuye a su titular el poder de resguardar ese ámbito reservado por el individuo para sí y su familia de una publicidad no querida ${ }^{14}$.

En el siglo XXI sigue vigente el ancestral castigo que ha perdurado durante miles de años, el encarcelamiento de la persona. Y aún no nos hemos planteado un cambio de paradigma.

La cárcel en el siglo XXI sigue siendo el medio más utilizado para condenar a una persona, y si la persona ha de permanecer en ella, hemos que variar los medios de ejecución junto con el sistema penitenciario. Un sistema que no sólo recoge en su articulado, como señalábamos anteriormente apuntando al artículo 82.2 del R.P, ideas propias de otro tipo de sociedad claramente atávica, sino que aún permanece en él, la vejación del preso, los malos tratos, los calabozos inhumanos y la tortura.

Cuestiones estas que han sido denunciadas por el Observatorio para la Defensa de los Derechos y Libertades ${ }^{15}$.

${ }^{14}$ S.T.C. 231/1988, de 2 de diciembre, F.J. 3; S.T.C. 236/2007, de 7 de noviembre, F.J.11 ${ }^{\circ}$. Y S.T.C. 60/2010 de 7 de octubre, F.J. $8^{\circ}$.

15 ESCULCA. Observatorio para la Defensa de Derechos y Libertades. Diario El País, de 24 de noviembre. Madrid. 2017. 
Igualmente, por los sindicatos de Prisiones, los propios reclusos, la Oficina del Defensor del Pueblo o el Comité Internacional Contra la Tortura, entre otros ${ }^{16}$.

Hechos que son reflejo, una vez más, de lo urgente y necesario que resulta el cambio de paradigma en el que se desenvuelve nuestro actual sistema penitenciario. Incluyendo una remoción de puestos de trabajo que permita llevar a cabo el verdadero sentido de la pena.

Los funcionarios de las cárceles en la actualidad son quienes, en última instancia, implementan las políticas diseñadas por la Administración Penitenciaria y en consecuencia deben ser tomados en consideración si se quiere que dichas políticas tengan éxito.

Pero ¿han de seguir siendo en su mayoría funcionarios de vigilancia como actualmente ocurre? ¿O la finalidad de la pena de prisión hace necesaria una remoción de puestos de trabajo en favor de otros profesionales?

Lo cierto es que si incluimos la I.A. para el diseño de nuevas políticas penitenciarias más acorde con el actual siglo XXI abandonando los ancestrales castigos, hemos de diseñar programas y ejecutar sentencias teniendo en cuenta los factores etiopatogénicos que influyen en la conducta violenta que han llevado a la persona a transgredir las normas y entrar en el campo de lo delictual.

El principal problema que se plantea es la inexistencia de un Instituto de Estudios Penitenciarios de carácter criminológico que desarrolle este proyecto.

16 ACAIP. Asociación Cuerpos de la Administración en Instituciones Penitenciarias. "Se investigan las condiciones en que cuatro prisioneros fueron detenidos en una celda" El sindicato señala los hechos como constitutivos de tortura, sufrimiento físico - mental, rigor innecesario y violación de los derechos fundamentales del recluso". Denuncia presentada contra la Dirección del Centro Penitenciario de Dueñas. Juzgado de Instrucción N. . . 2 de Palencia. De 11 de julio de 2017.

MECANISMO NACIONAL DE PREVENCIÓN CONTRA LA TORTURA. Prevención y Supervisión de lugares de privación de libertad en España, de acuerdo con el Protocolo facultativo a la Convención de las Naciones Unidas contra la tortura y otros tratos o penas crueles, inhumanos o degradantes (OPCAT) Oficina del Defensor del Pueblo. Madrid, 2019.

A.P. Cádiz, Secc. $4^{\mathrm{a}}$. Se condena a dos funcionarios de prisiones a penas de 1 a 3 años de cárcel, respectivamente por torturar y lesionar a un interno que había ingresado en prisión provisional en la cárcel de Puerto II. Hechos ocurridos en Cádiz, junio de 2017.

T.S. confirma la sentencia de la A.P. Sevilla de mayo de 2018 de tres años de prisión, diez años de inhabilitación y el pago de una multa de $3.960 €$, a un funcionario de prisiones por abusar sexualmente de una interna y vejar a otra en el Centro Penitenciario de mujeres. Hechos ocurridos entre 2012 y 2014 en Alcalá de Guadaira. Diario de Sevilla. 2020. 
Otro de los factores influyentes es el tiempo, ya que expertos en este tipo de materia desarrollada mediante I.A. hablan de, al menos un trienio para alcanzar un objetivo como este.

Y si bien es cierta la complejidad y coste en el desarrollo de una legislación penitenciaria de este calado, no es menos cierto que al elaborarse mediante la recogida de datos propios, es decir, pertenecientes a una sociedad concreta, la importación de sistemas penitenciarios de otros países, como viene ocurriendo desde hace siglos, sería innecesaria, convirtiéndose a su vez en más eficaz la desarrollada para cada Estado concreto aunque la base de todo ello fuesen las teorías criminológicas compartidas internacionalmente.

Un error frecuente en los programas que se desarrollan para determinadas patologías o adicciones es, verbigracia, la ausencia de factores individuales de aplicación a teorías generales. Ello ocurre por carecer los mismos, de aquellos datos cuya aplicación individualizada los haga más eficaces. Es decir, un programa para una adicción, por utilizar esta como ejemplo, debe incluir los factores concurrentes a un perfil de persona determinada, sino su eficacia será menor o nula. Los individuos pueden sufrir una misma adicción, pero su etiología puede ser distinta. Así la conocida teoría de la frustración de Agnew derivada del bloqueo de oportunidades, que podrían llevar al consumo de sustancias, ha de individualizarse científicamente. Sometiéndose así a una revisión sustancial por parte de la I.A. que haga más preciso alcanzar un pronóstico final individual más favorable.

Es por ello que, la apuesta de la I.A. para el desarrollo de este tipo de políticas legislativas se hace necesaria si de verdad creemos en el mandato constitucional del art. 25.2 de nuestra Carta Magna.

La ciencia criminológica bebe de numerosas fuentes, como son, el derecho, la psicología o la sociología, entre otras, a las que actualmente se une la de los algoritmos utilizados por la I.A.

No existe peligro en la utilización de la I. A. si se respetan los derechos de las personas y se hace una correcta utilización de sus aportaciones. No existe más riesgo del que puede derivarse de cualquier tecnología digital.

A este respecto, volvemos a recordar las palabras de la científica MARIE CURIE;

“(...) No debemos temer nada, solo debemos entenderlo”. 
Reservándose en mayor medida, como anunciábamos al principio, nuestra intimidad, frente al conocimiento de los demás, necesario, según las pautas de nuestra cultura, tal como sentencia el T.C. para mantener una calidad mínima de la vida humana.

\section{BIBLIOGRAFÍA}

Beccaria, Cesare. De los delitos y las penas. En: De la Prisión. Alianza Editorial. Salamanca, 2008.

Bermejo Cabrero, José Luis. Actas de las I Jornadas de Metodología Aplicada de las Ciencias Históricas, Vol. 2. Historia medieval. S.P. Santiago de Compostela. 1975.

Bernaldo De Quirós, Constancio. Las Nuevas Teorías de la Criminalidad. REUS. Madrid. 1908.

Bustos Ramírez, JuAn. El pensamiento criminológico, un análisis crítico. Editorial Temis. Bogotá 1983.

CABrerizo, Francisco. Las prisiones de Londres y las nuestras. Imprenta de Antonio Álvarez. Madrid, 1911.

Cancino T. Fabiola y Zegarra G. Javier. Síndrome Alcohólico Fetal. Revista de Neuro - Psiquiatría. UPCH. Perú, 2003.

Díaz Plaja, Fernando Memorias de la Historia. Planeta. Barcelona, 1996.

DiEgo Espinel, AndRÉs. Cárceles y reclusorios en el Antiguo Egipto. En Castigo y reclusión en el mundo antiguo. Editoras TORALLAS TOVAR, Sofia y PÉREZ MARTÍN, Inmaculada. Consejo Superior de Investigaciones Científicas. Madrid, 2003.

Fernandez Cruz, 2011: 206. En Serrano Tarraga, M. ${ }^{a}$ Dolores. Introducción a la Criminología. Dykinson. S.L. Madrid, 2017.

Gacto Fernández, EnRIQue. La vida en las cárceles españolas en la época de los Austria. Historia 16, Extra VII, octubre 1978.

GARRIDO GUZMÁN, Luis. Manual de Ciencia Penitenciaria. EDERSA. Madrid, 1983.

Guerrero López, José Francisco y Pérez Galán, Rafael. El alumnado con TDAH (hiperactividad) como colectivo en riesgo de exclusión social. Revista Ruedes. Año I. N. ${ }^{\circ}$ 2. Universidad de Málaga. 2011. 
GÜERRI FERnández, CRISTINA. De carceleros y ayudantes. El rol de los funcionarios de interior en los centros penitenciarios españoles. Atelier. Barcelona, 2020.

Hernandez Holgado, Fernando. Cárceles de mujeres en la España contemporánea. Dykinson. Madrid, 2017.

LARDizabal y URIBe De, MANuel (1782) Discurso sobre las penas contraído a las leyes criminales de España para facilitar su reforma. $2^{\text {a }}$ Ed. Imprenta de Repullés. Madrid, 1828.

Mommsen, Théodore. (1898) Derecho Penal Romano. Analecta. Pamplona, 1999.

Montesinos Molina, Manuel. Bases en que se apoya mi sistema penal. Revista de Estudios Penitenciarios. N. ${ }^{\circ} 159$. Madrid, 1962.

MuÑoz Pereira, JaVIER. La recepción en Europa de los sistemas penitenciarios norteamericanos. En Teorías Economicistas. Crítica. Dir. Carlos García Valdés. Edisofer. Madrid. 1997.

Ors, Álvaro de. Ulpiano, Domicio; Digesto de Justiniano Tomo III, Lib. 48, Tit. XIX, Frag. 8, Par. 9. Aranzadi, Pamplona. 1975.

OtÓn Sobrino, EnRIQue. SENECA, Lucio Anneo; De la cólera. VI. 1 y 2. Alianza. Madrid, 1986.

Pérez Marcos, Regina M. ${ }^{\text {a }}$ Un Tratado de Derecho Penitenciario del Siglo XVI. (Cerdán de Tallada, Thomas. Valencia 1567). Visita de la cárcel, y de los presos. UNED. Madrid.

Platon Diálogos. Tomo III. Gredos. Madrid. 1997.

Roxin, Claus. Derecho Penal. Parte General. Tomo I. Cívitas. Pamplona, 2015.

Ruiz-Pérez, Luis Miguel; Navia Manzano, José Antonio; Ruiz AmenGUAL, AiXA; y otros. Revista RETOS. núm. 29, enero - junio, Murcia, 2016.

Sanchez Tostado, Luis Miguel. El Simbolismo Iconográfico del Escudo de Prisiones. Diario de Jaén de 24 de septiembre. 1995.

SANZ BuRgos, RAúL. Ponencia: Inteligencia Artificial y Ética. Congreso I.A y DD.HH. UNED. 11 al 13 de noviembre. Madrid. 2019.

SERrano TARraga, M. ${ }^{a}$ Dolores. Introducción a la Criminología. Dykinson. S.L. Madrid, 2017.

SERRANo TARRAga, M. ${ }^{a}$ Dolores. Introducción a la Criminología. Dykinson. S.L. Madrid, 2017. 
Serrano Tarraga, M. ${ }^{a}$ Dolores. Introducción a la Criminología. Dykinson. S.L. Madrid, 2017.

Tomas Y Valiente, Francisco. Las cárceles y el sistema penitenciario bajo los Borbones. En Historia 16., 1978.

Vazouez Rosado, Angie. Causas de la conducta criminal. Revista de Psicología científica. UIPR. Puerto Rico, 2004. 